\title{
The scope of social attention deficits in autism: Prioritized orienting to people and animals in static natural scenes
}

\author{
Joshua J. New ${ }^{1}$, Robert T. Schultz ${ }^{2}$, Julie Wolf ${ }^{2}$, Jeffrey L. Niehaus ${ }^{3}$, Ami Klin $^{2}$, Tamsin C. \\ German $^{3}$, and Brian J. Scholl ${ }^{1}$ \\ ${ }^{1}$ Yale University, Department of Psychology \\ ${ }^{2}$ Yale University, School of Medicine, Child Study Center \\ ${ }^{3}$ University of California, Santa Barbara, Department of Psychology
}

\begin{abstract}
A central feature of autism spectrum disorder (ASD) is an impairment in 'social attention' - the prioritized processing of socially-relevant information, e.g. the eyes and face. Socially relevant stimuli are also preferentially attended in a broader categorical sense, however: observers orient preferentially to people and animals (compared to inanimate objects) in complex natural scenes. To measure the scope of social attention deficits in autism, observers viewed alternating versions of a natural scene on each trial, and had to 'spot the difference' between them — where the difference involved either an animate or inanimate object. Change detection performance was measured as an index of attentional prioritization. Individuals with ASD showed the same prioritized social attention for animate categories as did control participants. This could not be explained by lower-level visual factors, since the effects disappeared when using blurred or inverted images. These results suggest that social attention — and its impairment in autism - may not be a unitary phenomenon: impairments in visual processing of specific social cues may occur despite intact categorical prioritization of social agents.
\end{abstract}

\section{Introduction: Social Attention}

Humans are exceptionally social primates, and increasing evidence suggests that human social cognition is not simply the application of general cognitive abilities to social perception and behavior, but may reflect the operation of distinct specialized processes (e.g. Adolphs, 2006; Saxe, Moran, Scholz, \& Gabrieli, 2006). Evidence of dedicated mechanisms for social perception and attention has come from a wide array of sources. Neuroscientific research has identified several brain areas that seem specialized for social information processing, such as the superior temporal sulcus (e.g. Allison, Puce, \& McCarthy, 2000) and

\footnotetext{
Address for reprints and correspondence: Joshua New, Department of Psychology, Yale University, Box 208205, New Haven, CT 06520-8205, Joshua.New@ale.edu, brain.scholl@yale.edu, Web : http://www.yale.edu/perception/, Phone : 203-432-2518. Author Note: JJN is now at the Department of Psychology, Barnard College, New York City, NY. RTS is now at the Center for Autism Research, Department of Pediatrics, Children's Hospital of Pennsylvania, Philadelphia, PA.

Publisher's Disclaimer: This is a PDF file of an unedited manuscript that has been accepted for publication. As a service to our customers we are providing this early version of the manuscript. The manuscript will undergo copyediting, typesetting, and review of the resulting proof before it is published in its final citable form. Please note that during the production process errors may be discovered which could affect the content, and all legal disclaimers that apply to the journal pertain.
} 
the medial prefrontal cortices (Schultz et al, 2003). Clinical studies have identified specific neuropsychological deficits for categories of social information such as face recognition, as in prosopagnosia (e.g. Farah, Levinson, \& Klein, 1995). Experimental psychology has revealed social phenomena such as reflexive gaze following (e.g. Frischen, Bayliss, \& Tipper, 2007). And developmental psychologists have demonstrated that processes related to social evaluation operate even in infants as young as 6 months (e.g. Hamlin, Wynn, \& Bloom, 2007). The scope of social information that has been implicated in such studies is also enormous, varying from simple cues to animacy in moving geometric shapes (e.g. Gao, Newman, \& Scholl, in press; Heider \& Simmel, 1944) to the most nuanced inference of emotions as expressed in the eyes (e.g. Baron- Cohen, Wheelwright, \& Joliffe, 1997).

However, these many types of social information have often been at least implicitly regarded as products of an integrated social perception system - the 'social brain' (e.g. Brothers, 1990). Indeed, such results (and the importance of social information more generally) have even lead some to suggest that primates' large brains are due in considerable part to their need to navigate a complex social world (e.g. Byrne \& Whiten, 1988; Hermann, Call, Hernández-Lloreda, Hare, \& Tomasello, 2007; Humphrey, 1976).

Nevertheless, it is possible to evaluate the extent to which social perception is a single and fully integrated network of faculties. It may be, instead, that social perception results from a group of distinct processes that are only conceptually grouped together - and that may stand or fall separately in developmental disorders. In particular, it is possible to constrain these possibilities by studying the ways in which social perception is and is not selectively impaired in individuals with autism spectrum disorder.

\subsection{Impaired Social Perception and Attention in Autism Spectrum Disorder}

Specific impairments in social perception and attention are seen in a variety of neuropsychological contexts, such as prosopagnosia (e.g. Farah et al, 1995) and amygdala damage (e.g. Adolphs \& Spezio, 2006). However, the most prevalent such impairments are seen in individuals (especially children) with autism spectrum disorder (ASD) who have long been noted for their striking lack of interest in - and their lack of responsiveness to people, social interactions, and communicative behaviors (Kanner, 1943). ASD is in part defined by its pervasive disruptions of social abilities (Klin, Jones, Schultz, Volkmar, \& Cohen, 2002) and so represents a singularly informative disorder for uncovering the psychological architecture underlying social perception and cognition.

Individuals with ASD exhibit a number of abnormalities in visual attention - some of which are general in nature (e.g. Goldstein, Johnson \& Minshew, 2001) — but many of which are specific to the social domain. Children with ASD are markedly inattentive to faces (Osterling \& Dawson, 1994), show poorer facial identity discrimination (e.g. Klin et al, 1999; Tantam, Monaghan, Nicholson, \& Stirling, 1989), fixate the eye region of the face less (e.g., Dalton et al, 2005; Jones, Carr, \& Klin, 2002), and make less frequent and abnormally timed eye contact (Dawson, Osterling, Meltzoff, \& Kuhl, 2000; Sigman, Mundy, Ungerer, \& Sherman,1986). Even when they do attend to faces, they may process them in the much the same manner as inanimate objects (Schultz et al., 2000), or fail to reliably attend to facial expressions per se (Adolphs, Sears, \& Piven, 2001; Hobson, 1988; Klin et al., 2002; Weeks 
\& Hobson, 1987). While their attention may be automatically cued by eye gaze in some situations (Kylliäinen \& Hietanen, 2004; Swettanham, Condie, Campbell, Milne, \& Coleman, 2003; cf. Chawarska, Klin, \& Volkmar, 2003) but not in others (Ristic et al, 2005), children with ASD certainly have significant impairments in interpreting the meaning and social significance of the 'language of the eyes' (Baron-Cohen, Joliffe, Mortimore, \& Robertson, 1997; Baron-Cohen, Wheelwright, \& Joliffe, 1997). In a more abstract realm, children with ASD fail to spontaneously attribute the social meanings that typically developing children automatically ascribe to displays of simple moving geometric shapes (Abell, Happé, \& Frith, 2000; Klin, 2000; Rutherford, Pennington, \& Rogers, 2006) and they fail to efficiently process social information in point-light displays (Blake, Turner, Smoski, Pazdol, \& Stone, 2003; Klin, Jones, Schultz, \& Volkmar, 2003; Klin, Lin, Gorrindo, Ramsay, \& Jones, 2009). All of these impairments, however, can commonly occur in the context of normal intellectual levels, indicating a pattern of impairments specific to social abilities (e.g. Sturm, Ferneil, \& Gillberg, 2004).

\subsection{Categorical Animacy and the Scope of Social Cues}

Social cues, from the detection of animacy in simple shapes to the tracking of eye gaze, may be processed via a widespread but interacting network of neural regions — the 'social brain' (Brothers, 1990). Each neurologically-distinct region in this large network may underlie separate and functionally-specific processes of social cognition (Adolphs, 2003), but even the most rudimentary perception of animacy appears to activate the entire social network (Schultz et al, 2003; Wheatley, Millville, \& Martin, 2007). This raises the question of the scope of impairments in social attention and perception in ASD. ASD could be characterized by multiple distinct disruptions to individual cognitive processes (e.g. face perception, gaze following, etc.). Or, such deficits could instead arise from a single impairment to an earlier ('upstream') form of social perception (Pasley, Mayes, \& Schultz, 2004) that then has cascading deleterious effects on the downstream processing of specific social cues. These downstream effects could occur directly, via disruptions in typical patterns of information flow, or could occur indirectly, via disrupting the normal accumulation of socially relevant experiences (Schultz, 2005). For example, one group of models proposes that a lack of attention to social stimuli hinders the development of social perceptual faculties, most notably face and speech perception (Daw son et ah, 2005; Grelotti, Gauthier, \& Schultz, 2002). However, it is as yet unclear whether such inattention to social information results from a failure to find social information intrinsically rewarding or from some lower-level perceptual processes failing to direct attention to social information (Schultz, 2005).

Resolving these issues will clearly continue to require many studies exploring various types of social perception. In the present paper we seek to contribute to this project with a case study of what is perhaps the most abstract form of social processing: the categorical perception of animacy. Beyond specific cues such as eye gaze (and perhaps certain motion patterns), we also categorize the world into animate (and thus socially relevant) objects vs. inanimate objects, on the basis of their visual features. The category of animate objects obviously includes people, but also animals. The category of inanimate objects obviously includes manmade artifacts (such as toasters and chairs), but also biological entities such as plants. The categorization of entities into animate vs. inanimate objects occurs reliably and 
early in development (e.g. Gelman, 1990; Keil, 1983; Mandler \& McDonough, 1998), and is typically associated with higher-level cognition.

However, recent evidence suggests that this categorical distinction also influences the distribution of attention. Such effects are demonstrated in change detection, wherein observers have to identify the difference between two alternating versions of a natural scene - a task that can be surprisingly difficult even for quite salient changes ('change blindness'; Rensink, 2002; Rensink, O’Regan, \& Clark, 1997; Simons \& Rensink, 2005). However, not all changes are created equal. For example, observers tend to prioritize attention to certain specific social cues such as faces compared to other categories (e.g. Ro, Russell, \& Lavie, 2001). More generally, a recent study (New, Cosmides, \& Tooby, 2007) demonstrated that changes (such as reflections or deletions) made to animate agents (people or animals) were detected more readily and frequently than equivalent changes in inanimate objects (artifacts or plants). This may reflect an inherent prioritization for attending to animate agents, which were of considerable and persisting biological importance in our ancestral environments (New et al, 2007).

\subsection{The Current Case Study: Categorical Social Cues in ASP}

In the present experiment we employ the change detection paradigm as a case study to help assess the scope of social attention impairments in ASD, and in particular to reveal the extent to which individuals with ASD show prioritized attention for categorical animacy. In each trial, observers - children and young adults with ASD, control children, and control adults - viewed alternating versions of a natural scene, and had to detect and then identify the change between them (see Figure 1). No information was given about what types of objects might change. Notably, this task requires that participants exercise a degree of volition and spontaneity which is more reflective of real-world perception than many past types of attentional measures (e.g. spatial cueing).

Recent studies have revealed that individuals with autism are able to effectively complete change detection tasks, and studies of non-social cues using such tasks have revealed that they selectively attend to the same general properties of object arrays and scenes as do typically-developed observers (e.g. Burack et al, 2009). For example, individuals with autism detect changes made to regions that are judged to be central to a natural scene sooner than changes made to marginal regions (Fletcher-Watson, Leekam, Turner, Moxon, 2006), and they find changes made to contextually-inconsistent objects sooner than changes made to contextually-consistent objects (Fletcher-Watson et al., 2006; but see Loth, Gómez, \& Happé, 2008). Both of these results are also characteristic of typically developed observers (Hollingworth \& Henderson, 2000; Rensink et al., 1997). In addition, one prior study of a specifically social cue observed that individuals with autism detected changes to eye gaze direction more readily than changes to eyeglasses (Fletcher-Watson, Leekam, Findlay, Stanton, 2008).

Note that if individuals with ASD prioritize attention to categorical animacy as well, this would not be primarily a null result (i.e. in terms of differences with respect to typical observers), but would rather be a surprising positive result (i.e. in terms of differences with respect to animate vs. inanimate information). This would constitute a latent ability that 
could be unexpected, given most previous research demonstrating social perceptual impairments of many kinds in ASD.

In the present study, the changing target in each scene was either an animate object (a person or animal) or an inanimate object (a plant or artifact) that either reversed its orientation or repeatedly disappeared and reappeared (see Figures 1 and 2). Change detection performance (in terms of both speed and accuracy) was measured as an index of automatic attentional prioritization for each type of object (Tse, 2004).

\section{Method}

\subsection{Participants}

The participants were drawn from three different groups: (a) children and young adults with ASD, recruited at the Yale Child Study Center ( $\underline{n}=31$ ); (b) typically developing children also recruited at the Child Study Center ( $\underline{n}=8)$; and (c) non-clinical adults recruited at the University of California, Santa Barbara ( $\underline{n}=27)$.

The typically developing children were screened for psychopathology using the Child Symptom Inventory (Gadow \& Sprafkin, 1994) as well as phone interviews which asked about history of psychiatric illness. The children ( 7 males, 1 female) had an average age of 9.8 years $(\mathrm{SD}=1.6)$ and a mean IQ in the Above Average Range (Wechsler Abbreviated Scales of Intelligence. WASI; Weschler, 1999). The TD children were not matched to the clinical group with respect to demographic factors such as age or full-scale IQ. Differences in such factors are typically controlled because they might account for performance deficits in the clinical group relative to the TD groups. To foreshadow this study's results, however, there were no such differences in performance with respect to the hypotheses about semantic category, and thus such matching is not critical. The non-clinical adults were UC Santa Barbara undergraduates who participated for credit in an introductory psychology course.

The participants with ASD were diagnosed and recruited on the basis of parental interview (Autism Diagnostic Interview - Revised. ADI-R; Rutter, LeCouteur, \& Lord, 2003) and direct observations of participants' social and communicative behaviors (Autism Diagnostic Observation Schedule. ADOS; Lord, Rutter, DiLavore, \& Risi, 1999). All participants met criteria for ASD in both instruments, and received a clinician-assigned summary diagnosis of ASD by two experienced clinicians. Intellectual level was measured using the Wechsler Intelligence Scale for Children, third edition, WISC-III (Wechsler, 1991). Social adaptive functioning was measured with the Vineland Adaptive Behavior Scales, expanded form (Sparrow, Balia, \& Cicchetti, 1984). The final sample of participants with ASD (30 males, 1 female) had an average age of 10.8 years $(\mathrm{SD}=3.4)$, an average Vineland socialization standard score of 60.1 ( $\mathrm{SD}=12.8$ ), an ADOS socialization algorithm total of $7.9(\mathrm{SD}=3.4)$, an ADI-R social domain score of 21.6 ( $\mathrm{SD}=9.2)$, and an FSIQ score of $104.4(\mathrm{SD}=21.6)$.

\subsection{Stimuli and Apparatus}

The stimuli were color photographs of natural scenes taken from commercially-available CD-ROM image galleries. A target object in each scene belonged to one of the four semantic categories (people, animals, plants, and artifacts; see Figure 2). Two alternate 
versions of each scene were created using Adobe Photoshop software: one in which the target was deleted and filled in with the surrounding background, and one in which the target object was reflected from left to right. Fourteen scenes were created for each semantic category (for a total of 56 image sets). Nine adult control participants viewed the same scenes as the child and young adult participants; nine viewed inverted versions of each scene (see Figure 3a), and nine viewed the same scenes after they had been filtered with a Gaussian blurring function (Adobe Photoshop, 6 pixel kernel blurring; see Figure 3b). Such manipulations preserve many low- level visual properties of the images while attenuating effects of the images' semantic content (Kelley, Chun, \& Chua, 2007; New et al, 2003). The displays were presented on a Dell computer with an LCD display, controlled by E-Prime (Psychology Software Tools, Inc.; www.pstnet.com/eprime).

\subsection{Procedure and Design}

Non-clinical child participants and participants with ASD were tested individually in a private testing room at the Yale Child Study Center, and made their responses via a computer mouse. Non-clinical adult control participants were tested in groups of one to nine in a large room with semi-private workstation cubicles, and made responses with a computer mouse and keyboard.

In each trial, a black fixation cross appeared in the center of the display for $1000 \mathrm{~ms}$. A scene was then presented for $500 \mathrm{~ms}$ followed by a white masking screen for $120 \mathrm{~ms}$. The alternate version of the scene was then displayed for $500 \mathrm{~ms}$, followed again by a white masking screen for $120 \mathrm{~ms}$ (see Figure 1). This sequence was repeated until the participant detected the changing object, as indicated by a mouse click. If no response was made after 20 s, the trial was terminated, and the response coded as a 'miss'. After a response (or after 20s had elapsed), the original scene (with the target present) was displayed, and the participant identified the changing object by making a second mouse-click on the relevant region of the scene. Immediate feedback was then provided, by directly alternating the two images (again for 500ms per image) without an intervening mask, rendering the change obvious (Rensink, 2002; Rensink et al., 1997).

Participants completed four practice trials followed by 56 experimental trials presented in a different random order for each participant. The target objects in each category were changed an equal number of times for both types of changes (addition-deletion, left-right reflection).

\section{Results}

Detection responses occurring within 20s were coded as hits, as long as the identification response then fell within $1 \mathrm{~cm}$ of the target object's nearest boundary (unless that location occurred within another discrete object). The response latency for each semantic category was calculated as the mean response time for all 'hits' involving that category. There was no effect of change type (addition-deletion, left-right reflection) on either response time or accuracy, nor did it interact with semantic category in any of the three participant groups (all ps > .15). Performance was therefore collapsed across this variable for the analyses reported below.

Neuropsychologia. Author manuscript; available in PMC 2018 August 21. 


\subsection{Non-Clinical Adult Control Participants}

Analyses with non-clinical adult control participants replicated the semantic category effect first reported by New et al. (2007). Omnibus repeated-measures MANOVAs revealed a main effect of semantic category on both response time $\left[\mathrm{F}(3,6)=67.52, \mathrm{p}<.01\right.$, partial $\left.\eta^{2}=.97\right]$ and accuracy $\left[\underline{F}(3,6)=6.06, \underline{p}=.03\right.$, partial $\left.\eta^{2}=.75\right]$. As suggested by Figure $4 c$, this was driven by the considerably greater speed and frequency of detecting changes to targets in both animate categories (people and animals) compared to targets in both inanimate categories (plants and artifacts). These impressions were verified by the relevant pairwise statistical comparisons, as reported in Table 1 .

As an indication that these effects were largely driven by the categorical differences themselves rather than solely by lower-level visual differences, such effects were not reliable when inverted images were used (tested in a subgroup with the same size, and thus the same statistical power, as the upright-image subgroup; RT: $\underline{\mathrm{F}}(3,6)=1.62, \mathrm{p}=.28$, partial $\eta^{2}=.45$; Accuracy: $\underline{\mathrm{F}}(3,6)=3.08, \underline{\mathrm{p}}=.11$, partial $\left.\eta^{2}=.61\right)$ - a pattern that was also true in the initial report of New et al. (2007). In the subgroup of the same size tested with blurred images, the significant effect of category on accuracy reflects a partial reversal in performance between animate and inanimate objects $\left(\mathrm{RT}: \underline{\mathrm{F}}(3,6)=2.32, \underline{\mathrm{p}}=.18\right.$, partial $\eta^{2}=.54$; Accuracy: $\underline{\mathrm{F}}(3,6)=13.94, \underline{\mathrm{p}}<.01$, partial $\left.\eta^{2}=.87\right)$. These means, from best to worst, were: artifacts $(85 \%)$, animals $(83 \%)$, plants $(81 \%)$, and people $(71 \%)$. This suggests that the lower-level visual factors in these scenes actually competed with the categorical salience, such that our observed means with upright nonblurred images may be underestimating the influence of categorical animacy. It is possible, of course, that these image categories might still differ haphazardly in lower-level factors such as luminance, size, and eccentricity, but the results of our control analyses effectively rule out the possibility that such factors were responsible for the primary effects, since all of these factors were maintained in the control conditions too, but nonetheless yielded no reliable differences in the predicted direction in performance between animate and inanimate detection. Because the inversion and blurring manipulations were intended as a control for the image sets themselves (rather than for any feature of subjects' performance), we can be confident that such factors are not responsible for any animate/ inanimate differences obtained with this image set, in any population.

\subsection{Typically Developing Child Control Participants}

In the typically developing children, there was a marginally significant effect of semantic category on both response time $\left[\mathrm{F}(3,5)=4.99, \mathrm{p}=.06\right.$, partial $\left.\eta^{2}=.75\right]$ and percent correct $\left[\underline{F}(3,5)=6.06, \underline{p}=.06\right.$, partial $\left.\eta^{2}=.74\right]$, As Figure 4a illustrates (and as the pairwise comparisons in Table 1 confirm), these effects were driven by the greater detection performance for changes to animate objects compared to those made to inanimate objects. Moreover, the difference in response times for changes to animate vs. inanimate targets was comparable to that in the adult sample (a roughly $1500 \mathrm{~ms}$ effect). (The respective accuracy effect was much larger in the child sample, of course, since they had more overall errors.)

\subsection{Clinical Participants}

In the participants with ASD there was again a highly significant effect of semantic category on both response time $\left[\underline{F}(3,28)=23.6, \underline{p}<.01\right.$, partial $\left.\eta^{2}=.72\right]$ and percent correct 
$\left[\underline{F}(3,28)=19.55, \underline{p}<01\right.$, partial $\left.\eta^{2}=.68\right]$. As Figure $4 \mathrm{~b}$ illustrates (and as the pairwise comparisons in Table 1 confirm), this was again strongly driven by the considerably greater speed and frequency of detection for changing animate objects relative to inanimate objects. Moreover, the difference in response times for changes to animate vs. inanimate targets was comparable to those in both the adult and child control samples (a roughly 1500ms effect).

\subsection{Group Analyses}

To test for development trends, all of the participants were analyzed in a $3 \times 4$ mixed- model MANOVA which included all four semantic categories (as the within-subjects factor) and all three participant groups (as the between-subjects factor). As entailed by the preceding analyses, there were highly significant omnibus effects of semantic category on both response time $\left[\mathrm{F}(3,43)=29.86, \mathrm{p}<01\right.$, partial $\left.\eta^{2}=.68\right]$ and percent correct $[\mathrm{F}(3,43)=16.69$, $\mathrm{p}<01$, partial $\left.\eta^{2}=.54\right]$, in which RT and accuracy performance for detecting changes to animate objects exceeded that for inanimate objects. There were also significant effects of participant group on both RT $\left[\underline{\mathrm{F}}(2,45)=11.26, \underline{\mathrm{p}} .<.01\right.$, partial $\left.\eta^{2}=.33\right]$ and accuracy $\left[\underline{F}(2,45)=4.07, \underline{p} .=.02\right.$, partial $\left.\eta^{2}=.15\right]-$ though of course these baseline differences are not relevant for the category-specific questions under investigation here (and the present withinsubjects design does control for such individual differences). Participants with ASD were slower to detect changes than both nonclinical child controls [4679ms vs. $3622 \mathrm{~ms}$, $\mathrm{t}(37)=6.46, \mathrm{p} .<.01, \mathrm{r}=.73]$ and nonclinical adults [4679ms vs. $3280 \mathrm{~ms}, \mathrm{t}(38)=3.93, \mathrm{p} .<.01$, $\mathrm{r}=.54]$, Non-clinical children and adults, however, did not differ in their response speed [3622ms vs. 3280ms, $\mathrm{t}(15)=1.06, \mathrm{p}=.31, \mathrm{r}=.26$ ], Participants with ASD were comparable to nonclinical child controls [ $85 \%$ vs. $\left.92 \%, \mathrm{t}(37)=1.33, \mathrm{p}_{-}=.19, \mathrm{r}=.21\right]$, but lower in accuracy than nonclinical adult controls [ $85 \%$ vs. 97\%, $\mathrm{t}(37)=2.56, \mathrm{p}=.02, \mathrm{r}=.39$ ], Nonclinical adult controls were marginally significantly more accurate than nonclinical child controls [92\% vs. $97 \%, \mathrm{t}(37)=2.10, \mathrm{p}=.05, \mathrm{r}=.33]$.

Critically, however, there was no interaction between the participant groups and the particular semantic categories in either response time $\left[\underline{F}(6,88)=.88, \underline{p}=.51\right.$, partial $\left.\eta^{2}=.06\right]$ or percent correct $\left[\mathrm{F}(6,88)=1.14, \mathrm{p}=.35\right.$, partial $\left.\eta^{2}=.07\right]$. Thus, although preferential attention to people may grow slightly with age in participants with ASD (as reported below), the overall animate attentional bias (New et al, 2007) was evident and of roughly the same magnitude in each of our participants groups. (And in fact, the overall animate vs. inanimate effect was slightly but non significantly larger in the ASD group, indicating that this null interaction effect was not simply a result of insufficient statistical power.)

\subsection{Correlational Analyses}

Three indices of animate attentional biases were calculated, as the quotients of people over artifacts, animals over artifacts, and all animate objects over all inanimate objects. For example, an RT index of .50 for people over artifacts indicates that it took twice as long to detect changes to artifacts compared to changes to people. Greater animate attentional biases are thus indicated by smaller values of these indices for response times, but larger values for accuracy. Spearman correlations were used to evaluate whether any of the indices were related to the ASD participants' ages, clinical scores (Vineland, ADI, ADOS), or FSIQ. As Table 2 illustrates, there were no significant correlations between any of the three attentional 
bias indices and either clinical scores or FSIQ. There was, however, a significant negative correlation for RT: increasing age was associated with a faster detection of changes to people relative to artifacts (see Figure 4a). In contrast, there was no relationship between age and performance when considering animals relative to artifacts (see Figure $4 b$ ). The only significant correlation involving a clinical score - the ADI—suggests that increasingly higher scores (signalling a greater diagnosed severity of ASD) correspond to slower detection of changes to animals relative to artifacts - but since there was no hint of such an effect for changes made to people relative to artifacts, this clearly doesn't reflect any general weakening of the "animate advantage" with severity of ASD. There were no significant correlations between any of the factors when considering percent correct.

\section{Discussion}

The central result of this study was that children with ASD, despite their many social impairments, nevertheless exhibited robust social attentional biases for categorical animacy - detecting changes faster and more reliably to people and animals, compared to artifacts and plants. Moreover, these effects were of roughly the same magnitude as those exhibited in both children who were younger on average than the ASD participants, and adults who were older on average than the ASD participants.

\subsection{Spared Prioritization of Categorical Social Information in ASD}

The results of the single 'case study' experiment reported here go against the grain of many previous findings of impaired social information processing in ASD - e.g. in the perceptual processing of faces (e.g. Schultz et ah, 2000), eye gaze (e.g. Ristic et al., 2005), biological motion (e.g. Blake et ah, 2003; Klin et al, 2009), and the perception of animacy from simple motion cues (e.g. Klin, 2000). At the same time, the results reported here are in no way inconsistent with these previous reports, since they involve a different - and more abstract - type of social information, namely the categorical representation of perceived objects as animate or inanimate on the basis of a wide variety of visual surface features.

The case study of spared social attention reported here is a useful complement to the more commonly observed impairments, as it helps to constrain the scope of impaired social information processing in ASD. In particular, the results reported here, when considered in the context of the broader literature on impaired social information processing, raise the interesting possibility that 'social attention' — and its impairment in autism - may not be a unitary phenomenon: impairments in processing specific social cues (such as eyes and faces) may occur despite intact categorical prioritization of animacy. This makes it all the more important to continue investigating a diverse array of specific social cues in ASD, since they may not all stand or fall together.

\subsection{The Architecture of Social Attention}

What kind of cognitive architecture could explain this overall pattern of results - both the spared performance observed in our experiment, and the broader array of impairments? 'Categorical animacy' is prioritized in ASD (as indicated by our results), but such information may not be utilized in the same manner in downstream social processing, 
compared to typically developing children and adults. Just because you orient preferentially to certain types of information, in other words, doesn't mean that you know what to do with that prioritized information (cf. Schultz, et al, 2000).

Animate objects are strongly and reliably prioritized for attentional selection compared to inanimate objects in typically developing observers, even when little or no social information is involved. This prioritization is perhaps due to the differential biological salience of animate and inanimate objects in our species' ancestral environments (New et al, 2007): whereas people and animals very often presented exigent dangers or opportunities, plants and artifacts very often did not. Thus, preferentially attending to animate objects might not always be beneficial, but it could be invaluable for those cases when organisms encountered a potential predator or mate. (In contrast, learning to voluntarily attend to such information - especially in the context of predation — could be expensive, and a miss outweighs the cost of a false alarm.)

This type of attentional prioritization for animate information may thus arise from a perceptual mechanism that is phylogenetically separate from - and perhaps prior to - the processes involved in more socially-specific perceptual abilities. The results of the present case study - prioritized categorical animacy during change detection in the face of other social impairments - may reflect how animate objects are the subject of both 'animate attention' in a general sense, and of social information processing more specifically. This raises the interesting possibility that animacy and social information per se may be realized in distinct perceptual and cognitive mechanisms -with general processing of' categorical animacy' spared even while other specific forms of social processing are impaired.

\subsection{Future Directions}

It will be important for future research to evaluate the degree to which such sparing generalizes to other types of methods and displays, and to real-world social contexts. The spared attentional prioritization for animate objects observed here may in part result from the static nature of the stimuli. Individuals with ASD do preferentially fixate social information (i.e. eye regions) when viewing static scenes (Fletcher-Watson, Leekam, Benson, Frank, \& Findlay, 2009; Speer, Cook, McMahon, \& Clark, 2007) but not when viewing comparable dynamic scenes (Speer et al, 2007). Indeed, other types of perceptual faculties such as face perception may appear normal under drastically simplified laboratory conditions (e.g. van der Geest, Kemner, Verbaten, \& van Engeland, 2002), and yet be considerably disordered under more naturalistic viewing conditions (e.g. Klin, Jones, Schultz, Volkmar, \& Cohen, 2002). Increasing evidence, therefore, indicates that dynamic stimuli are necessary for accurately evaluating how individuals with ASD react to social information under more naturalistic conditions (Klin et al, 2003; Pelphrey, Morris, McCarthy, \& LaBar, 2007). It will thus be a priority in future work to explore prioritized attention to categorical animacy in both dynamic displays and in more naturalistic contexts.

Although there appeared to be no overarching developmental trajectory for the animate attentional bias in the nonclinical population, the small but significant increase of the effect with age for people in the group with ASD may also warrant further examination. Such developmental effects may reflect some compensatory processing strategies arising over 
time that may be sensitive to interventional approaches. We may have relatively reflexive biases to attend to animate information, but we could also learn to do so more overtly over time, just as high-functioning individuals with ASD learn to overtly compensate for other types of impaired mechanisms of social cognition (e.g. Golan \& Baron-Cohen, 2006).

\subsection{Conclusion}

Autism spectrum disorder has been widely recognized as a disorder that impacts many different processes, from relatively early types of perceptual processing (as in face recognition) to relatively high-level types of social cognition. However, the various processes recognized by cognitive psychologists have not all been equally studied in the context of ASD. In particular, while ASD researchers have paid considerable attention to both perception and cognition, they have not paid equal attention to ... attention. When attention has been studied in past research, it has sometimes been considered as a 'suspect' of sorts: perhaps various social impairments are due simply to the failure to attend to the relevant information (cf. Leslie, 2000). In contrast, the present case study illustrates how a focus on attention can reveal a type of spared categorical social processing, despite both disordered perception and cognition.

The present results constitute only a single study, and it remains an open question whether individuals with ASD will similarly attend preferentially to categorical animacy in either real-world situations or even in other experimental paradigms. However, the case study presented here does strongly suggest an underlying latent ability in individuals with ASD, irrespective of the specific conditions necessary to evoke it. This latent ability may seldom be expressed since it may be hindered by a host of other perceptual, cognitive, or taskrelated factors, but the current study reveals at least one paradigm — change detection with static images - in which this ability is expressed. We hope that this demonstration spurs additional questions and research on where and how such latent abilities may be preserved, but as yet uncovered.

\section{Acknowledgments}

We are indebted to Carla Brown, Dan Grupe, and Lauren Herlihy for assistance with data collection; to Max Krasnow for assistance with software development; and to the members of the Scholl and Chun laboratories at Yale University for helpful conversation and/ or comments on earlier drafts. JJN was supported by a National Research Service Award from NIMH. TG was supported by a grant from the M.I.N.D. Institute, UC Davis. BJS was supported by NSF grant \#BCS-0132444.

\section{References}

Abell F, Happé F, \& Frith U (2000). Do triangles play tricks? Attribution of mental states to animated shapes in normal and abnormal development. Cognitive Development. 15, 1-16.

Adolphs R (2003). Cognitive neuroscience of human social behavior. Nature Reviews Neuroscience. 4 165-178. [PubMed: 12612630]

Adolphs R (2006). How do we know the minds of others? Domain-specificity, simulation, and enactive social cognition. Brain Research, 1079, 25-35. [PubMed: 16507301]

Adolphs R, Sears L, \& Piven J (2001). Abnormal processing of social information from faces in autism. Journal of Cognitive Neuroscience, 13, 232-240. [PubMed: 11244548] 
Adolphs R, \& Spezio M (2006). Role of the amygdala in processing visual social stimuli In Anders S, Ende G, Junghofer M, Kissler J, \& Wildgruber D (Eds.), Progress in brain research: Vol, 156, Understanding emotions (pp. 363-378). Amsterdam, Netherlands: Elsevier.

Allison T, Puce A, \& McCarthy G (2000). Social perception from visual cues: Role of the STS region. Trends in Cognitive Sciences, 4, 267-278. [PubMed: 10859571]

Baron-Cohen S, Joliffe T, Mortimore C, \& Robertson M (1997). Another advanced test of theory of mind: Evidence from very high functioning adults with autism or Asperger syndrome. Journal of Child Psychology \& Psychiatry, 38, 813-822. [PubMed: 9363580]

Baron-Cohen S, Wheelwright S, \& Joliffe T (1997). Is there a "language of the eyes"? Evidence from normal adults, and adults with autism or Asperger syndrome. Visual Cognition, 4, 311-331.

Blake R, Turner LM, Smoski MJ, Pozdol SL, \& Stone WL (2003). Visual recognition of biological motion is impaired in children with autism. Psychological Science, 14, 151-157. [PubMed: 12661677]

Brothers L (1990). The social brain: A project for integrating primate behavior and neurophysiology in a new domain. Concents in Neuroscience. 1, 27-51.

Burack JA, Joseph S, Russo N, Shore DI, Porporino M, \& Enns JT (2009). Change detection in naturalistic pictures among children with autism. Journal of Autism and Developmental Disorders. 39, 471-479. [PubMed: 18807162]

Byrne R, \& Whiten A (Eds.). (1988). Machiavellian intelligence: Social expertise and the evolution of intellect in monkeys, apes, and humans. Oxford: Clarendon.

Chawarska K, Klin A, \& Volkmar F (2003). Automatic attention cueing through eye movement in 2year old children with autism. Child Development. 74, 1108-1122. [PubMed: 12938707]

Dalton KM, Nacewicz BM, Johnstone T, Schaefer HS, Gernsbacher MA, Goldsmith HH, et al. (2005). Gaze fixation and the neural circuitry of face processing in autism. Nature Neuroscience. 8, 519526. [PubMed: 15750588]

Dawson G, Osterling J, Meltzoff AN, \& Kühl P (2000). Case study of the development of an infant with autism from birth to two years of age. Journal of Applied Developmental Psychology, 21, 299-313. [PubMed: 23667283]

Dawson G, Webb SJ, Wijsman E, Schellenberg G, Estes A, Munson J, et al. (2005). Neurocognitive and electrophysiological evidence of altered face processing in parents of children with autism: Implications for a model of abnormal development of social brain circuitry in autism. Development and Psychopathology, 17,679-697. [PubMed: 16262987]

Farah MJ, Levinson KL, \& Klein KL (1995). Face perception and within-category discrimination in prosopaganosia. Neuropsvchologia, 33, 661-671.

Fletcher-Watson S, Leekam SR, Findlay JM, \& Stanton EC (2008). Young adults with autism spectrum disorder show normal attention to eye-gaze information-evidence from a new change blindness paradigm. Journal of Autism and Developmental Disorders. 38, 1785-1790. [PubMed: 18306031]

Fletcher-Watson S, Leekam SR, Turner MA. \& Moxon L (2006). Do people with autistic spectrum disorder show normal selection for attention? Evidence from change blindness. British Journal of Psychology, 97, 537-554. [PubMed: 17018188]

Frischen A, Bayliss AP, \& Tipper SP (2007). Gaze cueing of attention: Visual attention. social cognition. and individual differences. Psychological Bulletin. 133 694-724. [PubMed: 17592962]

Gadow KD, \& Sprafkin J (1994). Child Symptom Inventories Manual. Stony Brook. NY: Checkmate Plus.

Gao T, Newman GE, \& Scholl BJ (in press). The psychophysics of chasing: A case study in the perception of animacy. Cognitive Psychology.

Gelman R (1990). First principles organize attention to and learning about relevant data:Number and the animate-inanimate distinction as examples. Cognitive Science. 14, 79-106.

Golan O, \& Baron-Cohen S (2006). Systemizing empathy: Teaching adults with Asperger syndrome or high-functioning autism to recognize complex emotions using interactive multimedia. Development and Psychopathology, 18, 591-617. [PubMed: 16600069]

Goldstein G, Johnson CR, \& Minshew NJ (2001). Attentional processes in autism. Journal of Autism and Developmental Disorders. 31, 433-440. [PubMed: 11569589] 
Grelotti DJ, Gauthier I. \& Schultz RT (2002). Social interest and the development of cortical face specialization: What autism teaches us about face processing. Developmental Psychobiology. 40 213-225. [PubMed: 11891634]

Hamlin JK, Wynn K, \& Bloom P (2007). Social evaluation by preverbal infants. Nature. 450, 557-560. [PubMed: 18033298]

Heider F, \& Simmel M (1944). An experimental study of apparent behavior. The American Journal of Psychology, 57, 243-259.

Hermann E, Call J, Hernández-Lloreda MV, Hare B, \& Tomasello M (2007). Humans have evolved specialized skills of social cognition: The cultural intelligence hypothesis. Science. 317, 1360 1366. [PubMed: 17823346]

Hobson R (1988). What's in a face? The case of autism. British Journal of Psychology, 79, 441-453. [PubMed: 3208000]

Hollingworth A, \& Henderson JM (2000). Semantic informativeness mediates the detection of changes in natural scenes. Visual Cognition. 7, 213-235.

Humphrey NK (1976). The social function of intellect In Bateson P \& Hinde RA (Eds.) Growing Points in Ethology (pp. 303-317). Cambridge: Cambridge University Press.

Kanner L (1943). Autistic disturbances of affective content. Nervous Child. 2, 217-250.

Keil FC (1983). On the emergence of semantic and conceptual distinctions. Journal of Experimental Psychology: General. 112,357-385.

Kelley TA, Chun MM, \& Chua K -P. (2003). Effects of scene inversion on change detection of targets matched for visual salience. Journal of Vision. 3(1), 1-5, http://journalofVision.org/3/1/1/. [PubMed: 12678620]

Klin A, Jones W, Schultz R, Volkmar F, \& Cohen D (2002). Defining and quantifying the social phenotype in autism. American Journal of Psychiatry, 159, 895-908. [PubMed: 12042174]

Klin A, Sparrow SS, de Bildt A, Cicchetii DV, Cohen DJ, \& Volkmar FR (1999). A normed study of face recognition in autism and related disorders. Journal of Autism and Developmental Disorders. 6, 499-508.

Klin A (2000). Attributing social meaning to ambiguous visual stimuli in higher-functioning autism and Asperger syndrome: The Social Attribution Task. Journal of Child Psychology and Psychiatry, 41, 831-846. [PubMed: 11079426]

Klin A, Jones W, Schultz R, \& Volkmar F (2003). The enactive mind, or from actions to cognition: Lessons from autism. Philosophical Transactions of the Royal Society. Series B, 358, 345-360.

Klin A, Jones W, Schultz R, Volkmar F, \& Cohen D (2002). Visual fixation patterns during viewing of naturalistic social situations as predictors of social competence in individuals with autism. Archives of General Psychiatry, 59, 809-816. [PubMed: 12215080]

Klin A, Lin DJ, Gorrindo P, Ramsay G, \& Jones W (2009). Two-year-olds with autism orient to nonsocial contingencies rather than biological motion. Nature. 459, 257-261. [PubMed: 19329996]

Kylliäinen A, \& Hietanen J (2004). Attention orienting by another's gaze direction in children with autism. Journal of Child Psychology and Psychiatry, 45, 435-444. [PubMed: 15055364]

Leslie A (2000). "Theory of Mind" as a mechanism of selective attention In Gazzaniga M (Ed.) The New Cognitive Neurosciences (pp. 1235-1247). Cambridge, MA: MIT Press.

Lord C, Rutter M, DiLavore PC, \& Risi S (1999). Autism diagnostic observation schedule - WPS (ADOS-WPS1. Los Angeles, CA: Western Psychological Services.

Loth E, Gómez JC, \& Happé F (2008). Detecting changes in naturalistic scenes: Contextual inconsistency does not influence spontaneous attention in high-functioning people with autism spectrum disorder. Autism Research, 1, 179-188. [PubMed: 19360664]

Mandler JM \& McDonough L (1998). On developing a knowledge base in infancy. Developmental Psychology, 34, 1274-1288. [PubMed: 9823512]

New J, Cosmides L, \& Tooby J (2007). Category-specific attention for animals reflects ancestral priorities, not expertise. Proceedings of the National Academy of Sciences. 104, 16598-16603.

Osterling J, \& Dawson G (1994). Early recognition of children with autism: A study of first birthday home videotapes. Journal of Autism and Developmental Disorders. 24, 247-257. [PubMed: 8050980] 
Pasley BN, Mayes LC, \& Schultz RT (2004). Subcortical discrimination of unperceived objects during binocular rivalry. Neuron, 42, 163-172. [PubMed: 15066273]

Pelphrey KA, Morris JP, McCarthy G, \& LaBar KS (2007). Perception of dynamic changes in facial affect and identity in autism. Social Cognitive and Affective Neuroscience, 2, 140-149. [PubMed: 18174910]

Rensink RA (2002). Change detection. Annual Review of Psychology, 53, 245-277.

Rensink RA, O'Regan JK, \& Clark JJ (1997). To see or not to see: The need for attention to perceive changes in scenes. Psychological Science, 8, 368-373.

Ristic J, Mottron L, Friesen CK, Iarocci G, Burack JA \& Kingstone A (2005). Eyes are special but not for everyone: The case of autism. Cognitive Brain Research, 24, 715-718. [PubMed: 16099372]

Ro T, Russell C, \& Lavie N (2001). Changing faces: A detection advantage in the flicker paradigm. Psychological Science, 12, 94-99. [PubMed: 11294237]

Rutherford MD, Pennington BF, \& Rogers SJ (2006). The perception of animacy in young children with autism. Journal of Autism and Development Disorders, 36, 983-992.

Rutter M, LeCouteur A, \& Lord C (2003). The autism diagnostic interview, revised. Los Angeles, CA: Western Psychological Services.

Saxe R, Moran JM, Scholz J, \& Gabrieli J (2006). Overlapping and non-overlapping brain regions for theory of mind and self reflection in individual subjects. Social Cognitive and Affective Neuroscience, 1, 229-234. [PubMed: 18985110]

Schultz RT (2005). Developmental deficits in social perception in autism: The role of the amygdala and fusiform face area. International Journal of Developmental Neuroscience, 23, 125-141. [PubMed: 15749240]

Schultz RT, Gauthier I, Klin A, Fulbright RK, Anderson AW, Volkmar F, et al. (2000). Abnormal ventral temporal cortical activity during face discrimination among individuals with autism and Asperger syndrome. Archives of General Psychiatry, 57,331-340. [PubMed: 10768694]

Schultz RT, Grelotti DJ, Klin A, Kleinman J, Van der Gaag C, Marois R, \& Skudlarski P (2003). The role of the fusiform face area in social cognition: Implications for the pathobiology of autism. Philosophical Transactions of the Royal Society, Series B, 358, 415-427.

Sigman M, Mundy P, Ungerer J, \& Sherman T, (1986). Social interactions of autistic, mentally retarded, and normal children and their caregivers. Journal of Child Psychology and Psychiatry, 27, 647-656. [PubMed: 3771681]

Simons DJ \& Rensink RA (2005). Change blindness: Past, present, and future. Trends in Cognitive Science, 9, 16-20.

Sparrow SS, Balla DA, \& Cicchetti D (1984). Vineland adaptive behavior scales, expanded edition. Circle Pines, MN: American Guidance Service.

Speer LL, Cook AE, McMahon WM, \& Clark E (2007). Face processing in children with autism: Effects of stimulus contents and type. Autism, 11, 265-277. [PubMed: 17478579]

Sturm H, Ferneil E, \& Gillberg C (2004). Autism spectrum disorders in children with normal intellectual levels: Associated impairments and subgroups. Developmental Medicine \& Child Neurology, 46, 444-447. [PubMed: 15230456]

Swettenham I, Condie S, Campbell R, Milne E, \& Coleman M (2003). Does the perception of moving eyes trigger reflexive visual orienting in autism? Philosophical Transactions of the Royal Society of London. Series B, 358, 325-334. [PubMed: 12639330]

Tantam D, Monaghan L, Nicholson EE, \& Stirling J (1989). Autistic children's ability to interpret faces: A research note. Journal of Child Psychology \& Psychiatry, 30, 623-630.

Tse PU (2004). Mapping visual attention with change blindness: New directions for a new method. Cognitive Science. 28 241-258. [PubMed: 18797511]

van der Geest JN, Kemner C, Verbaten MN, \& van Engeland H (2002). Gaze behavior of children with pervasive developmental disorder toward human faces: A fixation time study. Journal of Child Psychology and Psychiatry, 43, 669-678. [PubMed: 12120862]

Wechsler D (1999). Wechsler Abbreviated Scale of Intelligence. San Antonio, Texas: Psychological Corporation. 
Wechsler D (1991). Wechsler Intelligence Scale for Children (3rd ed.). San Antonio, Texas: Psychological Corporation.

Weeks S, \& Hobson R (1987). The salience of facial expression for autistic children. Journal of Child Psychology and Psychiatry, 28, 137-151. [PubMed: 3558531]

Wheatley T, Milleville SC, \& Martin A (2007). Understanding animate agents: Distinct roles for the social network and mirror system. Psychological Science. 18, 469-474. [PubMed: 17576256] 


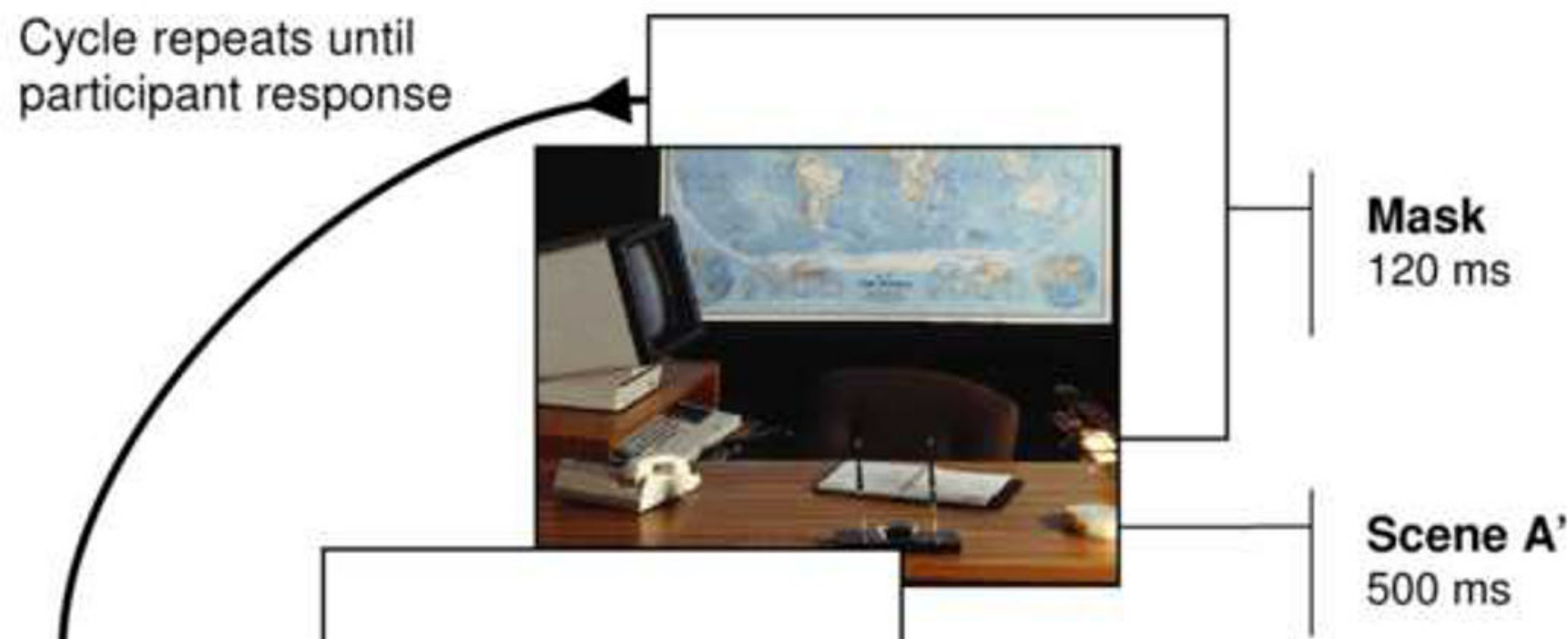

Figure 1.

A depiction of the change detection method: participants must detect and identify the difference between an original image and changed image. 


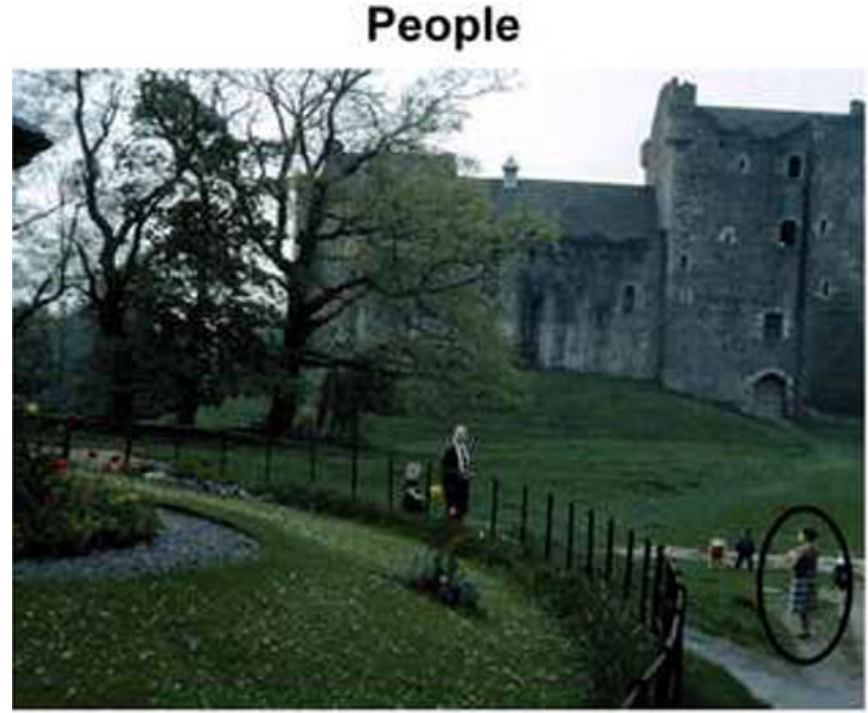

Plants

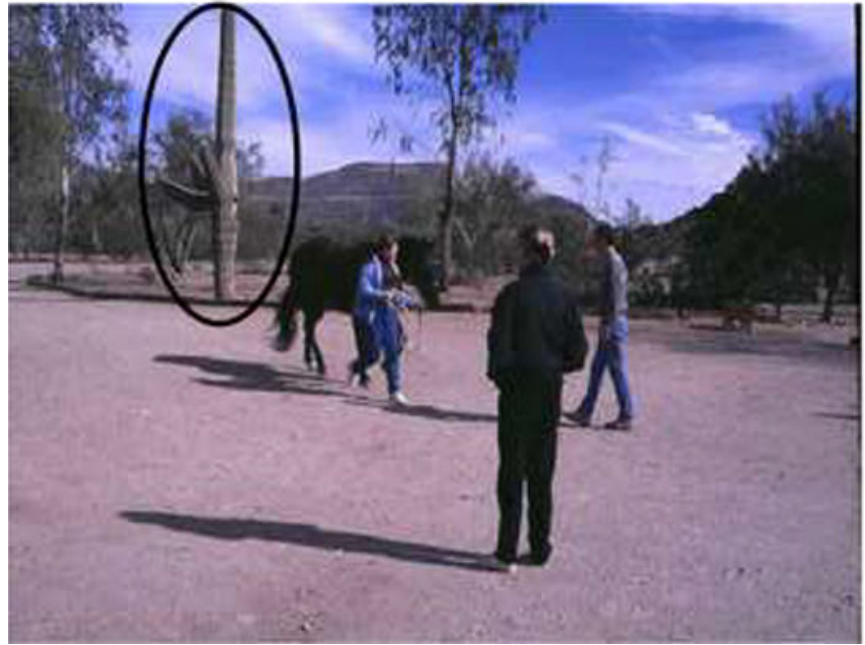

\section{Animals}

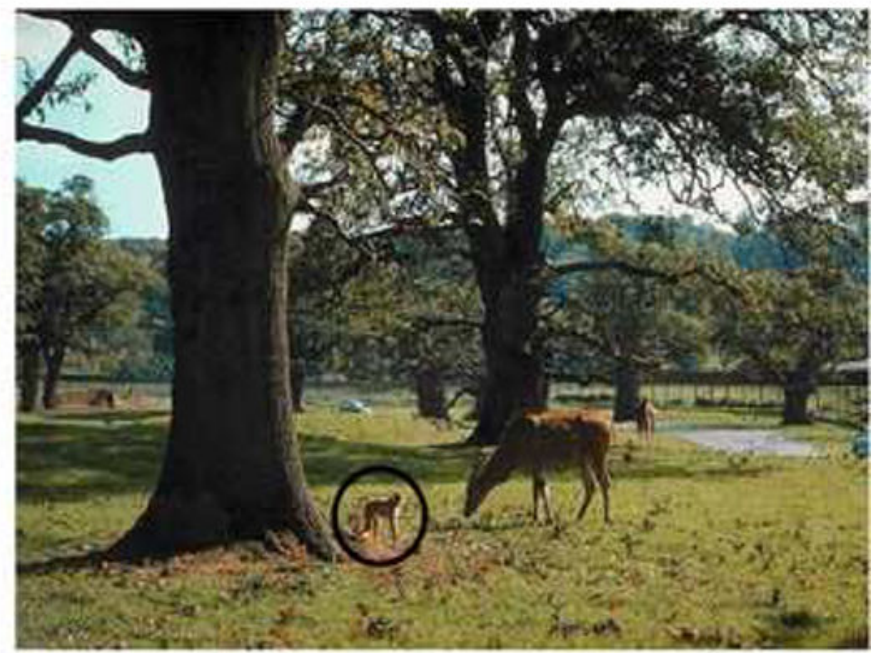

Artifacts

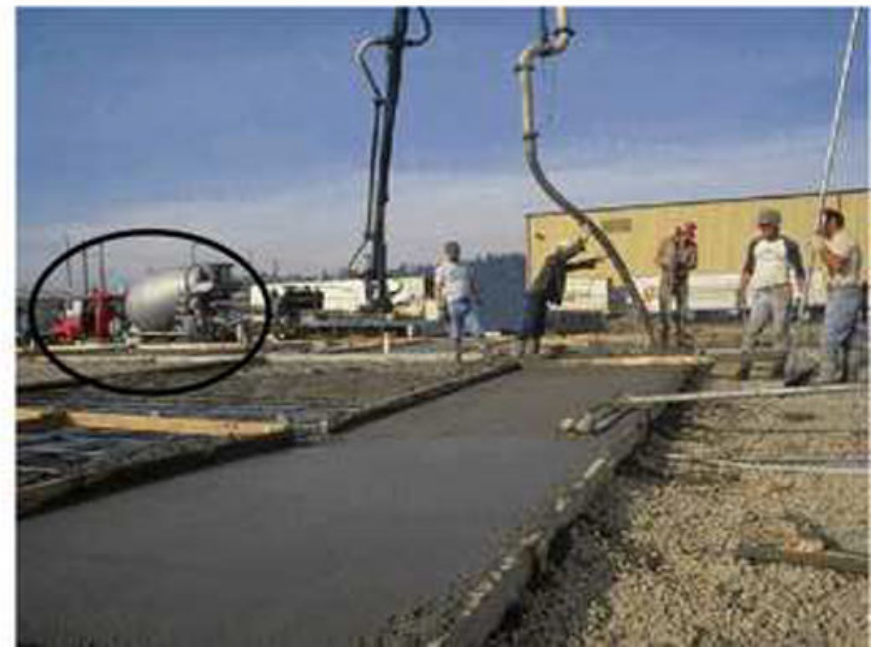

Figure 2.

Examples of each of the four scene categories. The target objects are circled here, but of course this highlighting was not present in the actual displays. 
Scene Inversion

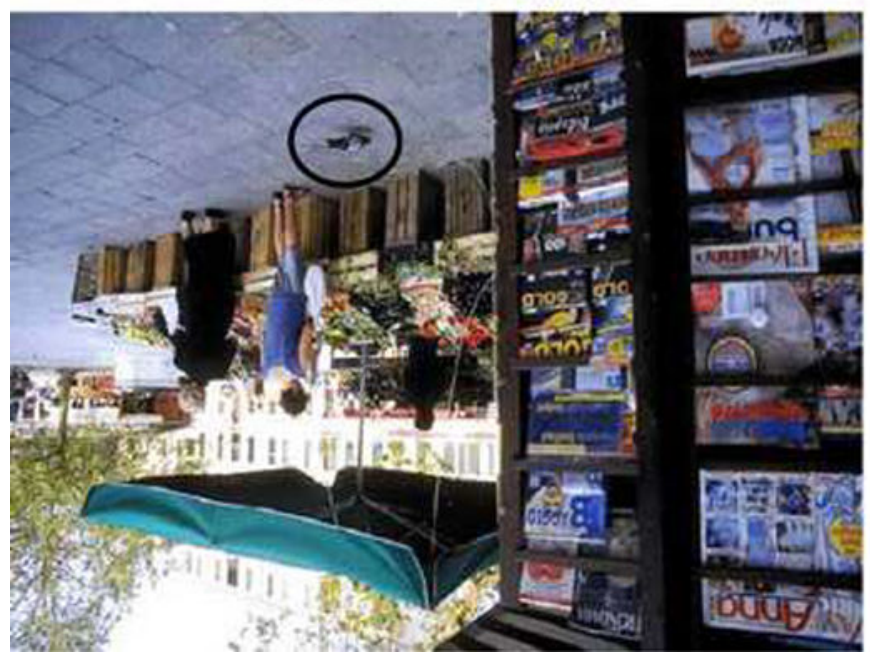

Scene Blurring

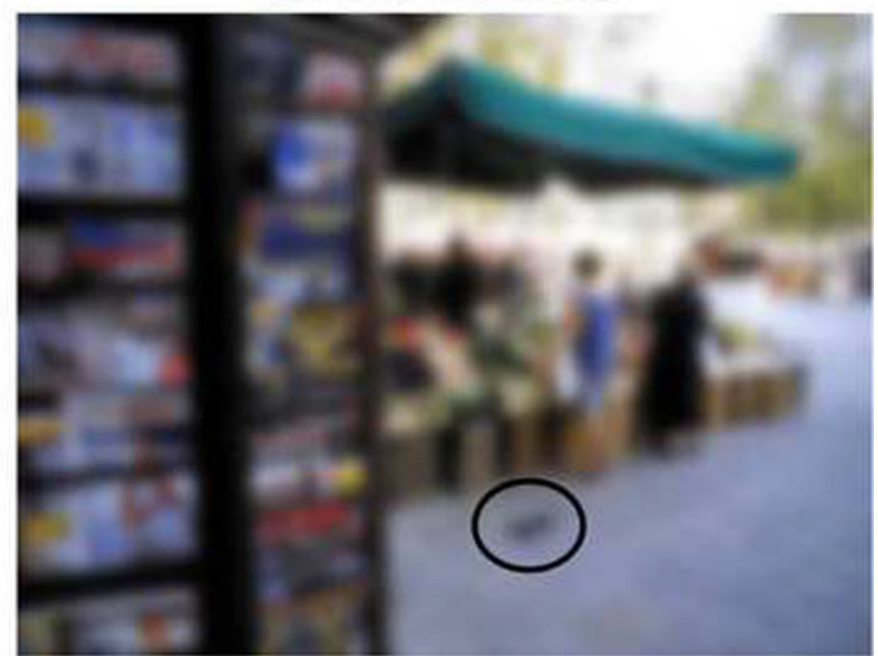

Figure 3.

Examples of the image manipulations used for the separate groups of adult control participants: (a) Scene inversion, and (b) Blurring. 


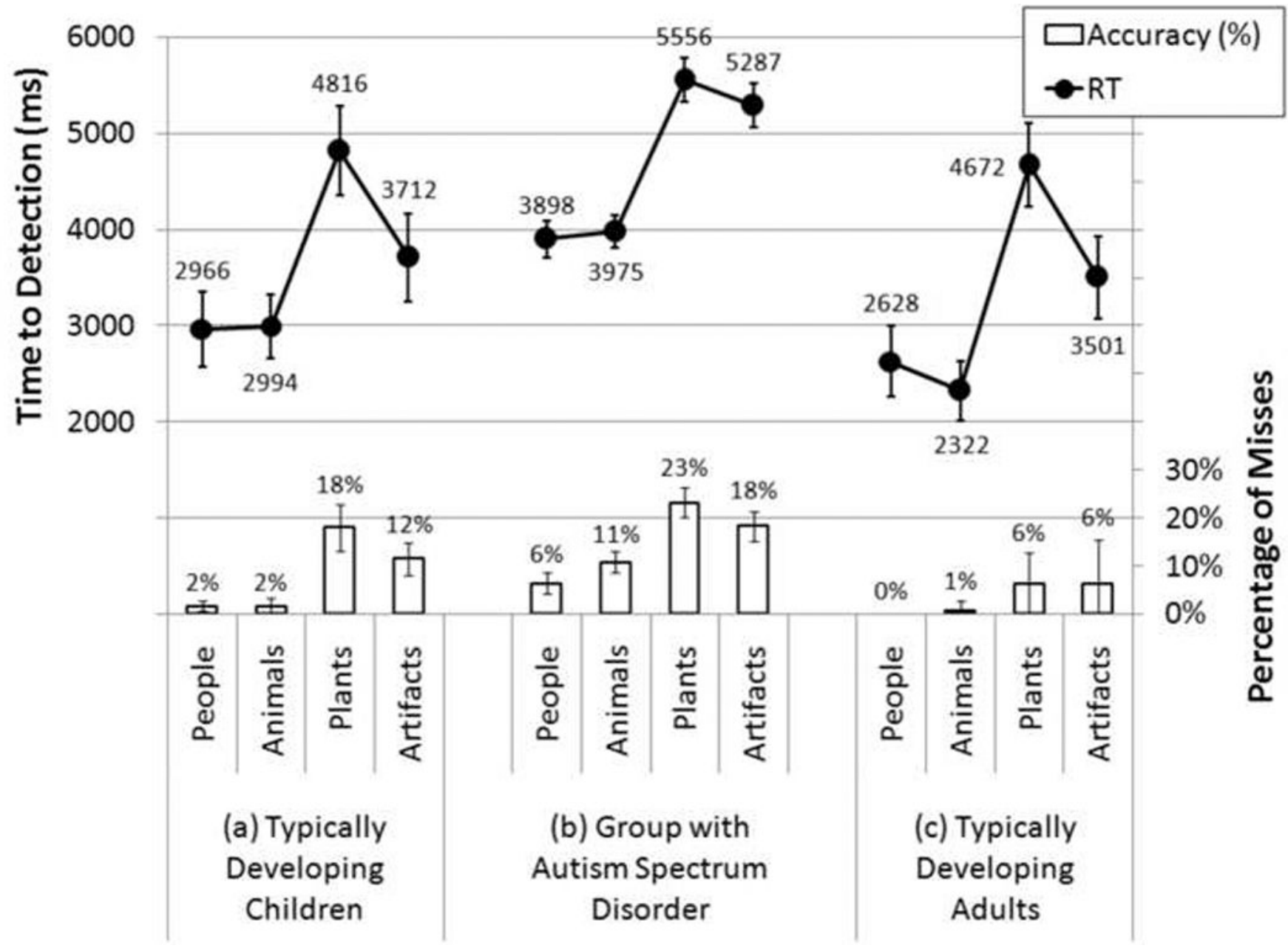

Figure 4.

Average change detection latency and accuracy for each of the four semantic categories (people, animals, artifacts, and plants) for each of the three participant groups: (a) typically developing child controls, (b) participants with ASD, and (c) adult controls. 
(a)

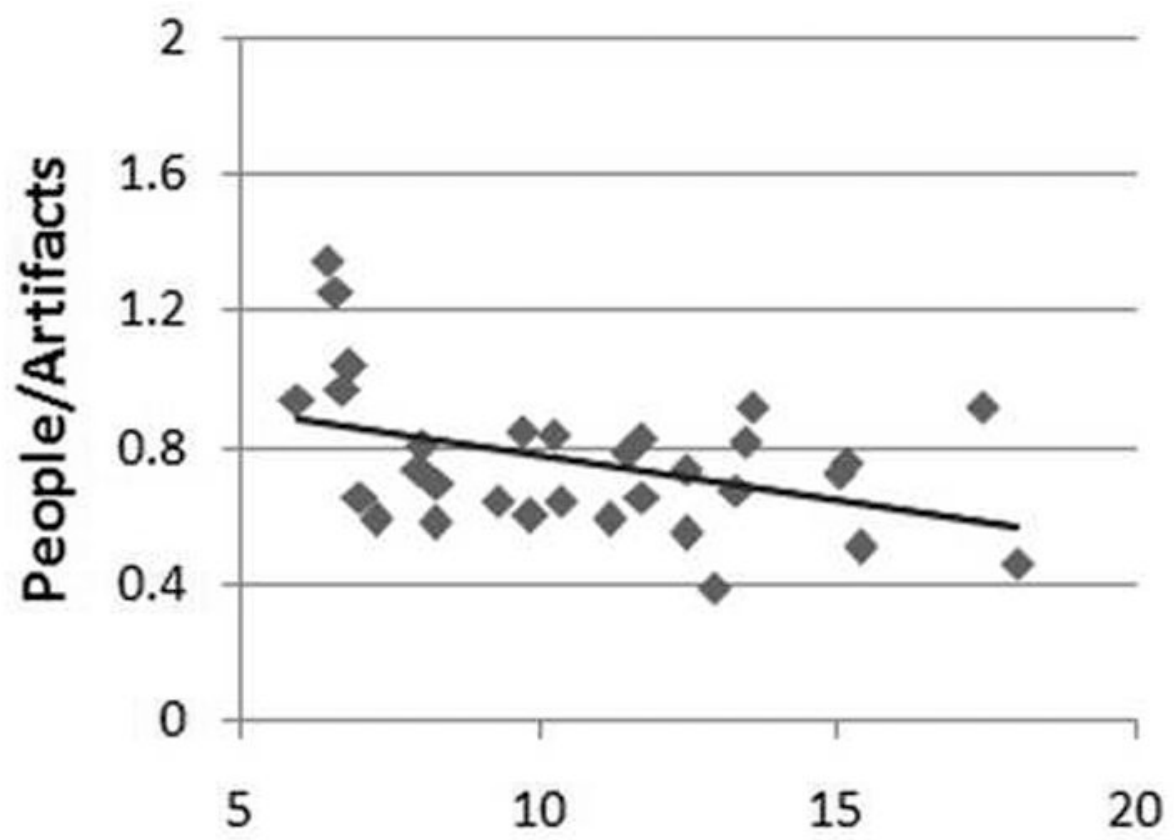

(b)

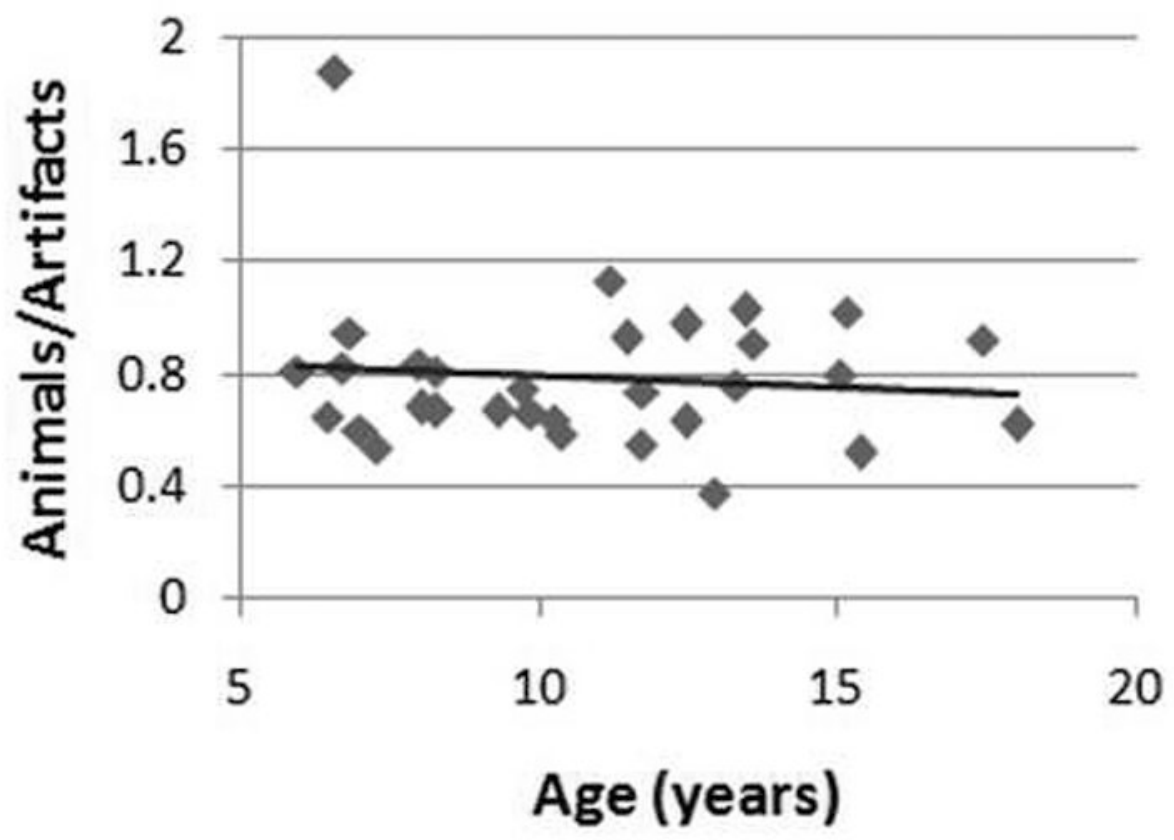

Figure 5.

Change detection latency as a function of ASD participant age for (a) people relative to artifacts, and (b) animals relative to artifacts. 

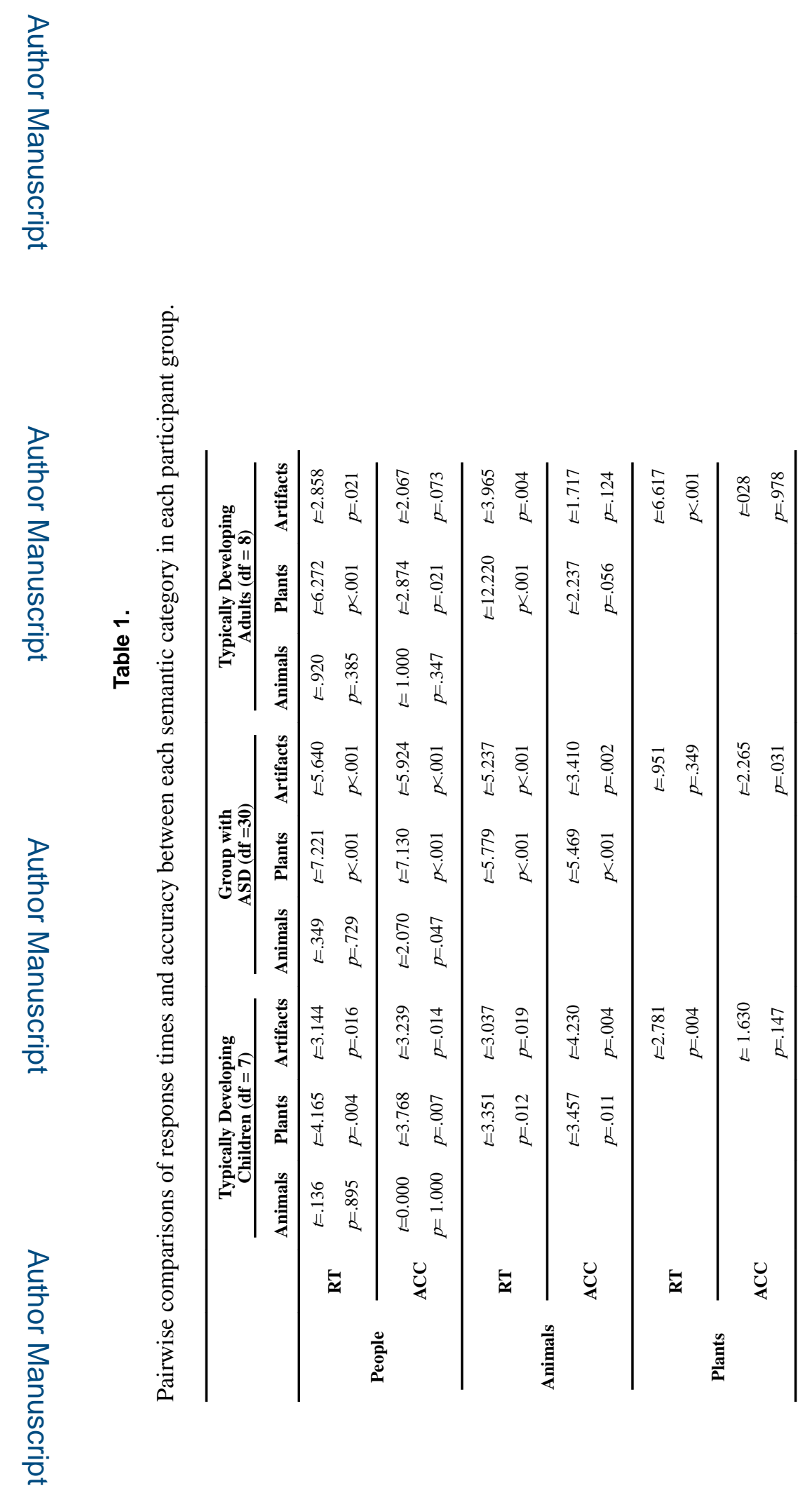

Neuropsychologia. Author manuscript; available in PMC 2018 August 21. 
Table 2.

Spearman correlations between each attentional index and clinical score. See text for details. P-values reflect one-tailed tests.

\begin{tabular}{|c|c|c|c|c|}
\hline & & $\begin{array}{c}\text { People/ } \\
\text { Artifacts }\end{array}$ & $\begin{array}{l}\text { Animals/ } \\
\text { Artifacts }\end{array}$ & $\begin{array}{c}\text { Animate/ } \\
\text { Inanimate }\end{array}$ \\
\hline \multirow{4}{*}{ AGE (31) } & \multirow{2}{*}{ RT } & $r=-.380$ & $r=-.027$ & $r=-.306$ \\
\hline & & $p=.018$ & $p=.442$ & $p=.047$ \\
\hline & \multirow{2}{*}{$\mathrm{PC}$} & $r=-.131$ & $r=.060$ & $r=-.165$ \\
\hline & & $p=.240$ & $p=.375$ & $p=.187$ \\
\hline \multirow{4}{*}{ ADOS (29) } & \multirow{2}{*}{ RT } & $r=-.110$ & $r=253$ & $r=.199$ \\
\hline & & $p=.285$ & $p=.092$ & $p=.150$ \\
\hline & \multirow{2}{*}{ PC } & $r=.180$ & $r=157$ & $r=.072$ \\
\hline & & $p=.176$ & $p=.209$ & $p=.355$ \\
\hline \multirow{4}{*}{ ADI (26) } & \multirow{2}{*}{ RT } & $r=-.085$ & $r=.496$ & $r=.259$ \\
\hline & & $p=.340$ & $p=.005$ & $p=.101$ \\
\hline & \multirow{2}{*}{ PC } & $r=.023$ & $r=.234$ & $r=.004$ \\
\hline & & $p=.456$ & $p=.125$ & $p=.491$ \\
\hline \multirow{4}{*}{$\begin{array}{l}\text { VINELAND } \\
\quad \text { (28) }\end{array}$} & \multirow{2}{*}{ RT } & $r=.242$ & $r=-.243$ & $r=.051$ \\
\hline & & $p=.107$ & $p=.106$ & $p=.398$ \\
\hline & \multirow{2}{*}{ PC } & $r=.036$ & $r=-.273$ & $r=005$ \\
\hline & & $p=.427$ & $p=.080$ & $p=.490$ \\
\hline \multirow{4}{*}{ FSIQ (29) } & \multirow{2}{*}{ RT } & $r=.152$ & $r=-.129$ & $r=.040$ \\
\hline & & $p=.216$ & $p=.252$ & $p=419$ \\
\hline & \multirow{2}{*}{ PC } & $r=-.221$ & $r=-.275$ & $r=-.200$ \\
\hline & & $p=.124$ & $p=.074$ & $p=.149$ \\
\hline
\end{tabular}

Neuropsychologia. Author manuscript; available in PMC 2018 August 21. 